\title{
Synthesis of Indoles, Pyrazoles, and Pyridazinones
}

Gategory

Synthesis of

Heterocycles

Key words

indoles

pyridazinones

pyrazoles

diazonium salts

alkenes
Significance: Reported is a one-pot synthesis of indoles, pyrazoles, and pyridazinones by a variation of the Japp-Klingemann Fischer indole synthesis, involving a trifluoromethylation. The reaction was found to well-tolerate a variety of functionalized arenediazonium salts and aryl allyl ketones. meta-Substituted arenediazonium salts provided mixtures of regioisomeric indoles (A and B). para-Substituted arenediazonium salts were also used with methyl pent-4-enoate to provide dihydropyridazinones in good yields.
Comment: The indole and pyrazole heterocyclic core is found in a number of top-selling drugs, such as sumatriptan, zolmitriptan, rizatriptan, tadalafil, and celecoxib (M. Baumann et al. Beilstein J. Org. Chem. 2011, 7, 442). Therefore, a simple and efficient synthesis of these heterocyclic cores is a worthwhile quest. The developed method gives access to various trifluoromethylated heterocycles. Previously, a similar methodology has been used to synthesize pyrazoles (A. Citterio et al. J. Heterocycl. Chem. 1981, 18, 763). Unexplained is the fact that all examples of dihydropyridazinone synthesis use para-substituted diazonium salt precursors.

SYNFACTS Contributors: Victor Snieckus, M. Selim Hossain (Snieckus Innovations) 